\title{
The Clinical and Epidemiological Spectrum of Multiple Sclerosis in Quito, Ecuador
}

Edgar Patricio Correa Díaz*, Angélica Ortiz Yépez, Germaine Torres Herrán, María Eugenia Buestan Zumba, Braulio Martinez Burbano, Victor Paredes Gonzalez, Carolina Jácome Sánchez, Vanessa Vásconez Dávalos, Juan José Zambrano Godoy, Estefania Flores Córdova, Evelyn Benalcázar, Josette Barros and Carla Acosta Vasquez

Department of Neurology, Hospital Carlos Andrade Marin, COOP IESS-FUT Oe5425, Quito 170601, Ecuador

*Corresponding author: Edgar Patricio Correa Diaz, Neurologist, Department of Neurology, Av. Universitaria, Hospital Carlos Andrade Marin, COOP IESS-FUT Oe5425, Quito, Ecuador, Tel: +593 0996794692; E-mail: patocorrea2010@yahoo.com

Rec date: Oct 23, 2016; Acc date: Oct 29, 2016; Pub date: Oct 31, 2016

Copyright: (c) 2016 Correa Diaz EP, et al. This is an open-access article distributed under the terms of the Creative Commons Attribution License, which permits unrestricted use, distribution, and reproduction in any medium, provided the original author and source are credited.

\section{Abstract}

Background: Multiple sclerosis (MS) is a chronic, degenerative autoimmune inflammatory disease leading to demyelination and axonal damage to the brain and spinal cord. This entity is low prevalence in Ecuador, and so far there are few reports regarding this disease.

Objective: To establish clinical and epidemiological characteristics of MS patients at Hospital Carlos Andrade Marín (HCAM) in the city of Quito, and to compare these findings with the reports published worldwide.

Methods: Using the McDonald criteria for diagnosis of MS 2010, we retrospectively reviewed the medical records of patients with MS who came to HCAM in Quito from January 2005 to December 2014. Degree of disability information, as well as clinical and demographic data was recorded. Then, a descriptive analysis of the data was performed.

Outcomes: 102 cases of multiple sclerosis were identified, the majority of which were female (female to male ratio of 2.2:1). The average age of this population was 39.6 years ( $S D+/-11.6)$, and the average age of symptom onset was 32 years (SD +/-11.1). The majority of cases corresponded to the recurrent remittent multiple sclerosis (RRMS) type at $93 \%$. Only 3 were progressive MS cases and 8 cases represented clinically isolated syndromes (CIS). Among the initial clinical manifestations, optical neuritis (ON) was present in $33 \%$ of cases, acute myelitis (AM) in $60 \%$ and $12.7 \%$ of patients debuted with brainstem manifestations. Motor, visual and sensory symptoms were the most common clinical manifestations established $(79 \%, 67 \%$ and $63.7 \%$, respectively). Cognitive and neuropsychiatric disorders were also common (56\% and $37 \%$, respectively). The average disability measured by The Expanded Disability Status Scale (EDSS) was 3.7.

Conclusion: This is the first descriptive study of a cohort of patients with MS from the City of Quito, Ecuador. The clinical and epidemiological characteristics of this cohort did not differ from those described worldwide.

Keywords: Multiple sclerosis; Optic neuritis; Transverse myelitis; Hospital Carlos Adrade Marín

\section{Introduction}

Multiple sclerosis (MS) is a chronic, degenerative, inflammatory autoimmune disease leading to demyelination and axonal damage to the brain and spinal cord $[1,2]$ In Latin America, the prevalence of MS is variable. The highest prevalence rates are found in countries like Mexico, Argentina, Uruguay and Brazil. For example, the prevalence in the state of Nuevo Leon, Mexico is 30 per 100,000 inhabitants. In Argentina, the prevalence is between 18 and 25 per 100,000 inhabitants near the equator the setting changes.

In Quito, Ecuador the estimated prevalence is 5.05 per 100,000 inhabitants, similar to that reported in neighbouring regions like Venezuela, Panama and Lima, Peru (5.26, 5.24 and 7.6 per 100,000, respectively) [3-6] These findings suggest that as we move away from the equator to the north or south, the number of cases of MS increases. However, several studies have shown that genetic susceptibility combined with environmental factors is what determines the prevalence of this disease [6].

None of the regions described above equal or exceed the prevalence found in North America or Europe: in the populations of England, Denmark and Norway the prevalence is greater than 100 cases per 100,000 (152, 129 and 112 per 100,000 inhabitants, respectively), which is very similar to that found in the northern United States and Canada (>100 cases per 100,000 inhabitants) [7,8].

In Ecuador there have been few epidemiological reports of the disease. Abad et al. conducted a capture-recapture study which came to identify 158 cases of MS. The city with the highest number of cases was Quito with 103 cases, followed by Guayaquil with 50 cases and Cuenca in which only 5 cases were identified. Females were the most affected (74\%) [9]. Alarcón, et al. conducted an observational study in a social security hospital of Guayaquil, the most populated city of Ecuador, in which 45 cases of MS were identified. Similar to the study of Abad et al., the highest number of cases was in females [10]. However, we do not have any more information about this disease in our country. 
Hospital Carlos Andrade Marín (HCAM) in Quito is a social security hospital. It is a national reference center for MS because it has a neuroimmunology unit which covers the costs of disease modifying agents (DMA), such as fingolimod and interferons, which often cannot be purchased by patients because of their high cost. For this reason, HCAM is the reference center with the largest number of MS cases in our country. In this context, the objective of this study is to determine the clinical and epidemiological characteristics of MS patients who come to HCAM and to compare these findings with the characteristics published worldwide.

\section{Patients and Methods}

The study was conducted at the Neurology Department at HCAM. Using the McDonald 2010 criteria, we retrospectively reviewed the medical records of patients with MS who came to HCAM between January 2005 and December 2014. This is a prospective observational study with longitudinal monitoring. Disease information was collected on each subject (details below). The study was approved by the Institutional ethics committee.

a) Inclusion criteria: This study included patients who met the diagnostic criteria established in 2010 by McDonald [11]. According to their clinical course, patients were classified into the following categories: Clinically isolated syndrome (CIS), Relapsing-remitting MS (RRMS), Primary progressive MS (PPMS) and Secondary progressive MS (SPMS) [12].

b) Source population and setting: The patients were recruited from the neuroimmnunology clinic (NIC) within the neurology department at HCAM of Quito, Ecuador. The information for each patient was acquired from the AS 400 computer system where Ecuadorian social security patient information is stored. HCAM is the largest hospital in the city of Quito and a referral center where patients come from central and northern Ecuador. All patients seen in the neuroimmunology clinic at HCAM were prospectively followed over time. The patient data were collected on a computer platform. HCAM is a social security hospital which provides and covers the cost of treatments, including disease modifying agents (DMA). The DMAs available at HCAM are interferons, fingolimod, mitoxantrone and immunosuppressants such as azathioprine, methotrexate and mycophenolate.

The study was performed in Quito, the capital of Ecuador, located at an altitude of 2,816 meters above sea-level, with a projected population of 2,505,344 inhabitants for the year 2014, according to the INEC (National Institute of Statistics and Censuses) [13]. The city has temperatures ranging from $8^{\circ} \mathrm{C}$ to $24^{\circ} \mathrm{C}$, and daylight that lasts 10 to 15 hours. The racial composition of this Andean city is represented by a Mestizo majority, a few Caucasians and a minority composed of Indigenous and Afro-Ecuadorians [9].

c) Exclusion criteria: Patients who did not fully meet the McDonald 2010 criteria for MS and CIS were excluded.

d) Data collection/study measures: After signing an informed consent, demographic and clinical characteristics were collected. The data recorded included: sex, age, education and duration of illness. Clinical and epidemiological information was also collected, including: age of onset of symptoms, age at diagnosis, type of MS, initial clinical manifestation and the Kurtzke Expanded Disability Status Scale or EDSS.

Neuropsychological evaluation was conducted through the Montreal Cognitive Assessment (MOCA), Paced Auditory Serial
Addition Task (PASAT), the Symbol Digit Modalities Test (SDMT, oral form), The California Verbal Learning Test-II (CVLT-II) and Brief Visuo-spatial Memory Test Revised (BVMT-R). Moreover, Hamilton depression and anxiety scales were conducted. Each of the tests was recorded and confirmed by two neurologists. The cognitive tests were performed by a neuropsychologist.

\section{The course of disease was defined as follows:}

CIS: It is defined by the presence of a clinical attack with objective evidence of lesion. Also, magnetic resonance image (MRI) studies of these patients showed lesions consistent with areas of demyelination that did not meet the criteria of dissemination in time (DIT) or space (DIS).

RRMS: It is the worsening of neurologic function (relapse) and improvement (remission). Relapse was defined as an acute deterioration of neurological function of 24 hours followed by a period of total or partial recovery.

SPMS: It was initially diagnosed with RRMS but now the disease progresses leading to increased disability with or without periods of relapse.

PPMS: It is the worsening of neurological function from the beginning of the disease.

e) Statistical analysis: Descriptive analyses were performed. Means and standard deviations for continuous variables, absolute and relative frequencies for categorical variables and the female to male ratio were calculated. For the computer system analysis SPSS version 21 was used.

\section{Results}

Between 2005 and 2014, 102 patients with MS were identified. Eight percent were CIS, $89 \%$ RRMS, 2\% SPMS and 1\% PPMS. Females were the most affected (69\%). The male/female ratio was $2.2: 1$. The average age of this population was 39.6 years $(\mathrm{SD}+/-11.6)$. The average age at onset of the disease was 32.6 years (SD+/-11.1) (Tables 1 and 2).

\begin{tabular}{|l|l|}
\hline Number of patients & 102 \\
\hline Males, $\mathrm{n}(\%)$ & $32(31 \%)$ \\
\hline Females, $\mathrm{n}(\%)$ & $70(69 \%)$ \\
\hline Male:Female ratio & 0.45 \\
\hline $\begin{array}{l}\text { Disease duration from Medical } \\
\text { diagnosis }\end{array}$ & Mean $+/-\mathrm{SD}$ \\
\cline { 2 - 3 } & $7.1+/-6.2$ \\
\hline Age at onset of 1st Symptom (years) & $32+/-11.10$ \\
\hline Age of this cohort (years) & $39.6+/-11.6$ \\
\hline \multirow{2}{*}{ Disease course } & CIS-8 (7.84\%) \\
\cline { 2 - 3 } & RRMS-91 (89.21\%) \\
\cline { 2 - 3 } & SPMS-2 (1.96\%) \\
\cline { 2 - 3 } & PPMS-1 (0.98\%) \\
\hline
\end{tabular}

SD: Standard Deviation; CIS: Clinically Isolated Syndrome; RRMS: Relapsing Remitting Multiple Sclerosis; SPMS: Secondary Progressive Multiple Sclerosis; PPMS: Primary Progressive Multiple Sclerosis

Table 1: Demographic profile of patients with multiple sclerosis. 


\begin{tabular}{|c|c|}
\hline \multirow{3}{*}{$\begin{array}{l}\text { Part of neuraxis involved in } 1 \text { st } \\
\text { relapse }\end{array}$} & Optic nerve-33.3\% \\
\hline & Spinal cord-59.8\% \\
\hline & Brainstem- $6.86 \%$ \\
\hline \multirow[t]{8}{*}{ Clinically established manifestations } & Motor symptoms-79\% \\
\hline & Sensory symptoms-63.7\% \\
\hline & Visual oculomotor disorders- $67 \%$ \\
\hline & Cerebellar symptoms- $13 \%$ \\
\hline & Urinary retention- $7 \%$ \\
\hline & Urinary incontinence-22\% \\
\hline & Constipation-7\% \\
\hline & Fetal incontinence-2\% \\
\hline \multirow[t]{4}{*}{ Cognitive impairment } & Verbal fluency-21\% \\
\hline & Spatial visual perception-21\% \\
\hline & Immediate memory $-14 \%$ \\
\hline & Attention- $11 \%$ \\
\hline \multirow[t]{2}{*}{ Neuropsychiatric manifestations } & Anxiety-25\% \\
\hline & Depression-30\% \\
\hline \multirow[t]{2}{*}{ EDSS of this cohort } & Mean \\
\hline & 3.7 \\
\hline $0-3$ & $44 \%$ \\
\hline $3.5-6.5$ & $49 \%$ \\
\hline$>7$ & $7 \%$ \\
\hline
\end{tabular}

Table 2: Clinical characteristics of MS subjects.

Of the 8 patients with CIS, four had ON; one case debuted with brain stem symptoms and three with acute myelitis (AM).

Among the initial clinical manifestations, $\mathrm{ON}$ was the first clinical expression in 33\%, AM (mainly partial or incomplete AM) occurred in $69.8 \%$ and brain stem symptoms were observed in $6.86 \%$. Seventeen percent of patients had initial involvement in two systems.

With regard to the clinically established manifestations, motor symptoms (weakness/spasticity) were the most frequent clinical manifestations (79\%), followed by visual disorders (67\%) and sensory symptoms (63.7\%). ON was present in $65 \%$ of cases, either as an initial clinical manifestation or as a relapse in the course of the disease. Cerebellar symptoms (dysarthria, ataxia and postural instability) were less frequent (13\%).

In neuropsychological assessment of patients, it was found that $56 \%$ had cognitive impairment, and that subcortical cognitive impairment was the most predominant. The cognitive functions which were most impaired were: verbal fluency and spatial visual perception (21\%), immediate memory (14\%) and attention (11\%). Of patients with cognitive disorders, $37 \%$ had a disease evolution of less than 5 years.
Anxiety disorder and depression were the most frequent neuropsychiatric manifestations ( $25 \%$ and $30 \%$, respectively). Anxiety disorder was more common in females (72\%).

Impaired sphincter control affected $28 \%$ of patients. Urinary retention was present in $7 \%$, and urinary incontinence was the most common symptom (22\%). Seven percent of patients had constipation and $2 \%$ experienced faecal incontinence. Sexual disorders are not well documented in our cohort. However, 2 patients reported having erectile dysfunction and 1 reported anorgasmia.

The general average EDSS in this cohort was 3.7. Forty-four percent of patients had an EDSS between $0 \%$ and $3.49 \%$ had between 3.5 and $6.5 \%$ and $7 \%$ had more than 7 .

\section{Details of the para-clinical studies}

According to the topography of lesions on MRI, the most frequent location of demyelinating lesions was periventricular (96\%), medullary (85.29\%) and juxtacortical (51.9\%), with the infratentorial location (cerebellum and brain stem) being less frequent (47\%). In relation to spinal cord injury, the most common location was in the cervical cord (51\%) and $11.7 \%$ had high spinal cord conditions. Oligoclonal bands were applied in 33 patients, in which $81 \%$ of cases were positive.

\section{Discussion}

Records of MS patient cases provide crucial information about the prevalence, incidence and symptoms of disease, as well as disability status and treatment possibilities. Unfortunately, only one such study has been carried out in Ecuador. Thus, we do not know the incidence of this disease in our country. However, observational studies like ours allow us to know the characteristics of the disease at the local level and help to estimate the problem at a national level.

In our study, as in the study of Abad et al. [9], and Alarcon et al. [10] the highest number of cases was female. The female to male ratio in the three studies was 2.3, 1.7 and 2.2:1 respectively [9,10] This predominance in the number of cases in women has also been demonstrated in a Canadian longitudinal study where it was found that the female to male ratio was 3.1:1. The reasons for this predilection in the female population are still unknown $[14,15]$.

In our cohort, the average age of onset of symptoms was 32 years, similar to the findings of an Italian study (28.3 years) [16], A Canadian study (30.6 years) [17] and of a French study (31 years) [18]. This disease primarily affects young people, as most patients in this study are between the ages of 20 and 55. The current average age of our population is 39.6 years-old and has similar demographic characteristics to the Italian study (40.6 years) [16-18].

After revision of the criteria for McDonald in 2005, the findings of new studies in MRI have suggested the need to simplify the criteria for early diagnosis. Accordingly, in 2010 a new consensus was held in this manner to simplify the concept of DIT and DIS through MRI, so that diagnosis of the disease could be performed simply through MRI study [11]. However, it should be mentioned that these criteria detracted from the clinical utility of spinal fluid analysis [11]. In applying these criteria to our patients, we found that 91 cases met the criteria for McDonald RRMS. In addition, three cases of progressive MS and 8 cases with CIS were found. We found few cases with progressive MS because most of these patients go to foundations or clinics specializing in patients with chronic diseases. 
Acute demyelinating $\mathrm{ON}$ is the most common initial clinical manifestation of MS, and is present in $15 \%$ to $20 \%$ of cases and occurs in up to $50 \%$ of cases throughout the course of the disease $[19,20]$ In the present study, acute demyelinating ON was present in $33 \%$ of cases as an initial symptom. However, $67 \%$ of our patients were affected at some point during the evolution of the disease.

The term transverse myelitis is defined as a motor, sensory and autonomic dysfunction disorder secondary to inflammatory damage of the spinal cord, and is common in MS [21] In other words; MS is the most common cause of acute myelitis (AM) [22]. In the current study, it presented as the initial symptom of MS in $60 \%$ of the cases.

Studies have shown that weakness affects $89 \%$ of patients at some point during their illness [23]. In our series, motor symptoms were found in $79 \%$ of cases. This is due to compromise of the corticospinal tract and is usually accompanied by upper motor neuron signs (hyperreflexia, spasticity and Babinski) [22]. Regarding sensory symptoms, numbness and paresthesias are common in patients with MS. According to published studies, they affect $87 \%$ of patients with MS [23]. In our series, these symptoms were present in $63.7 \%$ of cases, and paresthesias were the most common sensory symptoms.

Since the 1980s, several studies have shown that cognitive impairment is a common constant with MS patients, with prevalence rates ranging between $43 \%$ to $70 \%$ [24]. In our study, cognitive impairment was present in $56 \%$ of cases. The domains affected in our patients were: verbal fluency, visual-spatial perception, immediate memory and attention. Cognitive impairment progresses as the disease does, which was demonstrated by Strober et al. in a study involving 22 patients treated with IFN- $\beta$-1a IM. Neuropsychological evaluations of the patients were conducted over the course of 18 years. It was observed that cognitive impairment was present in $41 \%$ of patients at the baseline of the study, but eventually ended up affecting $59 \%$ of patients, suggesting that cognitive impairment in patients with MS progresses over time [25].

Hospital studies have shown that approximately $25 \%$ to $50 \%$ of MS patients develop a form of major depression during the course of their lives, which is two to five times higher than in the general population [26]. In our study, it was present in $30 \%$ of cases. Depression has been shown to be less common during the early stages of the disease than during the later stages [22]. Another common neuropsychiatric symptom in MS is anxiety disorder, with prevalence between $20 \%$ to $30 \%$. Much like the frequency of depression, the frequency of anxiety disorders in MS patients is much higher than in the general population [27]. This disorder was present in $25 \%$ of our patients. A retrospective study showed that anxiety disorders, but not depression disorders, reached higher levels of prevalence in females, suggesting a gender influence on the frequency of anxiety [28]. In our work, anxiety disorders were prevalent among females, occurring in 18 of 26 patients (70\%). With the frequency of psychiatric disorders for this population described above, our results do not differ from those published worldwide. These disorders add to the pre-existing disability, hence the importance of identification and treatment [27].

Neurogenic bladder is a major cause of disability in MS [29]. One of the most common manifestations of neurogenic bladder is detrusor hyper-reflexia, which is present in two-thirds of patients with MS. It presents with manifestations such as urinary urgency, frequency and incontinence [30]. These symptoms were present in 22 of our patients (21\%). Bowel dysfunction is less common than bladder dysfunction. Constipation was the most common complaint of patients with MS.
Bowel dysfunction in our cohort was present in seven patients, two of them reporting faecal incontinence similar to that which usually occurs in the context of severe spinal cord damage.

The limitation of our study is that It was not population based, leading to selection bias. Nevertheless, the fact that the demographic data in the present study are comparable to those reported in other epidemiological studies indicate that our results are representative of the overall population of MS patients in Ecuador and are similar to the published data from registries around the world.

\section{Conclusion}

This is the first observational study of a cohort of patients with MS in Quito. The demographic and clinical characteristics of our study do not differ from what has been previously published worldwide. ON and $\mathrm{AM}$ were the principal manifestations at onset of the disease, while weakness, visual disorders and sensory symptoms were the most frequent clinical symptoms established. We further note that neurocognitive abnormalities are common, and were present in about half of our patients. A nationwide registry will establish stronger data on the profile of MS in Ecuador.

\section{References}

1. Nylander A, Hafler DA (2012) Multiple sclerosis. J Clin Invest 122: 1180-1188.

2. Hauser SL, Chan JR, Oksenberg JR (2013) Multiple sclerosis: Prospects and promise. Ann Neurol 74: 317-327.

3. Melcon MO, Melcon CM, Bartoloni L, Cristiano E, Duran JC, et al. (2013) Towards establishing MS prevalence in Latin America and the Caribbean. Mult Scler 19: 145-152.

4. Cristiano E, Rojas J, Romano M, Frider N, Machnicki G, et al. (2013) The epidemiology of multiple sclerosis in Latin America and the Caribbean: a systematic review. Mult Scler 19: 844-854.

5. Cristiano E, Patrucco L, Rojas JI (2008) A systematic review of the epidemiology of multiple sclerosis in South America. Eur J Neurol 15: 1273-1278.

6. Aguirre-Cruz L, Flores-Rivera J, De La Cruz-Aguilera DL, Rangel-López E, Corona T (2011) Multiple sclerosis in Caucasians and Latino Americans. Autoimmunity 44: 571-575.

7. Kingwell E, Marriott JJ, Jetté N, Pringsheim T, Makhani N, et al. (2013) Incidence and prevalence of multiple sclerosis in Europe: a systematic review. BMC Neurol 13: 128.

8. Evans C, Beland SG, Kulaga S, Wolfson C, Kingwell E, et al. (2013) Incidence and prevalence of multiple sclerosis in the Americas: a systematic review. Neuroepidemiology 40: 195-210.

9. Abad P, Pérez M, Castro E, Alarcón T, Santibáñez R, et al. (2010) Prevalence of multiple sclerosis in Ecuador. Neurologia 25: 309-313.

10. Tomás Alarcón G, Rafael Aguirre N, Enrique Díaz C, Rocío Santibáñez V, Carlos Navas P (2011). Esclerosis Multiple en un Hospital del Litoral Ecuatoriano 20: 1-3.

11. Polman CH, Reingold SC, Banwell B, Clanet M, Cohen JA, et al. (2011) Diagnostic criteria for multiple sclerosis: 2010 revisions to the McDonald criteria. Ann Neurol 69: 292-302.

12. Jacques FH (2015) Defining the clinical course of multiple sclerosis: the 2013 revisions. Neurology 84: 963.

13. Instituto Nacional de Estadísticas (INEC). Población y demografía (2015) Disponible en: www.inec.gov.ec.

14. Orton SM, Herrera BM, Yee IM, Valdar W, Ramagopalan SV, et al. (2006) Sex ratio of multiple sclerosis in Canada: a longitudinal study. Lancet Neurol 5: 932-936. 
Citation: Correa Diaz EP, Ortiz A, Torres G, Buestan Zumba ME, Martinez B, et al. (2016) The Clinical and Epidemiological Spectrum of Multiple Sclerosis in Quito, Ecuador. J Neurol Disord 4: 312. doi:10.4172/2329-6895.1000312

Page 5 of 5

15. Ramagopalan SV, Byrnes JK, Orton SM, Dyment DA, Guimond C, et al. (2010) Sex ratio of multiple sclerosis and clinical phenotype. Eur J Neurol 17: 634-637.

16. Liguori M, Marrosu MG, Pugliatti M, Giuliani F, De Robertis F, et al. (2000) Age at onset in multiple sclerosis. Neurol Sci 21: S825-S829.

17. Confavreux C, Vukusic S (2006) Natural history of multiple sclerosis: a unifying concept. Brain 129: 606-616.

18. Frohman EM, Frohman TC, Zee DS, McColl R, Galetta S (2005) The neuro-ophthalmology of multiple sclerosis. Lancet Neurol 4: 111-121.

19. Balcer LJ (2006) Clinical practice. Optic neuritis. N Engl J Med 354: 1273-1280.

20. Frohman EM, Wingerchuk DM (2010) Clinical practice. Transverse myelitis. N Engl J Med 363: 564-572.

21. Jeffrey-Gelfand M (2014) Multiple sclerosis: diagnosis, differential diagnosis, and clinical presentation. In Michael J. Aminoff, Francois Boller, and Dick F. Swaab, (eds). Handbook of Clinical Neurology. Vol. 122. Amsterdam, The Netherlands. Elsevier 2: 269-291.

22. Swingler RJ, Compston DA (1992) The morbidity of multiple sclerosis. QJ Med 83: 325-337.

23. Chiaravalloti ND, De-Luca J (2008) Cognitive impairment in multiple sclerosis. Lancet Neurol 7: 1139-1151.
24. Strober LB, Rao SM, Lee JC, Fischer E, Rudick R (2014) Cognitive impairment in multiple sclerosis: An 18 year follow-up study. Mult Scler Relat Disord 3: 473-481.

25. Feinstein A, Magalhaes S, Richard JF, Audet B, Moore C (2014) The link between multiple sclerosis and depression. Nat Rev Neurol 10: 507-517.

26. Dahl OP, Stordal E, Lydersen S, Midgard R (2009) Anxiety and depression in multiple sclerosis. A comparative population-based study in NordTrøndelag County, Norway. Mult Scler 15: 1495-1501.

27. Théaudin M, Romero K, Feinstein A (2016) In multiple sclerosis anxiety, not depression, is related to gender. Mult Scler 22: 239-244.

28. De-Ridder D, Van Der Aa F, Debruyne J, D'hooghe MB, Dubois B, Guillaume D (2013) Consensus guidelines on the neurologist's role in the management of neurogenic lower urinary tract dysfunction in multiple sclerosis. Clin Neurol Neurosurg 115: 2033-2040.

29. Fowler CJ, Panicker JN, Drake M, Harris C, Harrison SC, et al. A UK consensus on the management of the bladder in multiple sclerosis. J Neurol Neurosurg Psychiatry 80: 470-477.

30. Chia YW, Fowler CJ, Kamm MA, Henry MM, Lemieux MC, et al. (1995) Prevalence of bowel dysfunction in patients with multiple sclerosis and bladder dysfunction. J Neurol 242: 105-108. 